Bella Kharisma Putri, Aldri Frinaldi I Dampak Budaya Kerja Aparatur terhadap Kualitas Pelayanan pada Program Plase Care Papa di Kabupaten Padang Pariaman

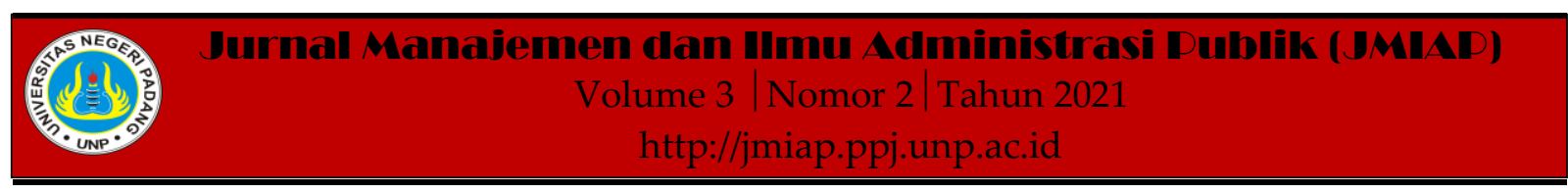

\title{
DAMPAK BUDAYA KERJA APARATUR TERHADAP KUALITAS PELAYANAN PADA PROGRAM PLASE CARE PAPA DI KABUPATEN PADANG PARIAMAN
}

\author{
Bella Kharisma Putri' ${ }^{1(a)}$, Aldri Frinaldi ${ }^{2(b)}$ \\ ${ }^{1}$ Jurusan Ilmu Administrasi Negara, Universitas Negeri Padang \\ ${ }^{2}$ Jurusan Ilmu Administrasi Negara, Universitas Negeri Padang \\ a)bellakharisma49@gmail.com, ${ }^{b}$ alfrinaldi@gmail.com
}

\begin{abstract}
This study aims to determine the impact of civil service work culture on service quality in the Please Care Papa program in Padang Pariaman Regency. Please Care Papa is an online service that is useful forhelp identify the needs of the poor based on profiles in an integrated database linking the poor to social protection and poverty alleviation programs carried out by the Central Government, Provincial Governments and District Governments according to the needs of the poor. The research method used is descriptive qualitative. The selection of informants was used by purposive sampling technique. In collecting data, the writer uses interview, observation and documentation techniques. The results of the research that have been carried out can be concluded that not all services can run with the online system seen from the target users of the Please Care Papa website are the poor who have limitations and the ability to technology. The lack of socialization provided to the community is also an obstacle in implementing this online service so that there are still many people who do not know about the online services provided by the Office for Women's Empowerment and Child Protection through the Please Care Papa website.

Keywords : Work Culture, E-Government Service Quality, Padang Pariaman Regency

Corresponding author. Email. bellakharisma49@gmail.com

How to cite this article. Putri, B. Kharisma \& Frinaldi, A. (2021). Dampak Budaya Kerja Aparatur terhadap Kualitas Pelayanan pada Program Plase Care Papa di Kabupaten Padang Pariaman. Jurnal Manajemen dan Ilmu Administrasi Publik (JMIAP) Jurusan Ilmu Administrasi Negara Fakultas Ilmu Sosial Universitas Negeri Padang, Volume 3 (2), Hal. 154-161.

http://jmiap.ppj.unp.ac.id

Copyright@2021. Published by Labor Jurusan Ilmu Administrasi Negara FIS UNP, Padang
\end{abstract}




\section{PENDAHULUAN}

Kemiskinan merupakan persoalan sosial yang bersifat pelik dan harus segera diatasi dengan penanganan yang seksama. Indonesia merupakan negara berkembang yang mempunyai jumlah populasi penduduk yang padat, tentu tidak dapat terhindar dari masalah tersebut. Ini dibuktikan dengan tingginya angka masyarakat miskin yang sebagian besar tinggal di daerah perkampungan karena sukar untuk dicapai. Bahkan di kota-kota besar juga tidak menutup kemungkinan juga banyak ditemukan masyarakat miskin (Widayani, 2013).

Kabupaten Padang Pariaman yang terletak di Provinsi Sumatera Barat, juga tidak lepas dari masalah kemiskinan. Angka kemiskinan di Kabupaten Padang Pariaman termasuk tinggi pada tahun 2018 diangka 8,04 persen dari 427 ribu jiwa masyarakat Padang Pariaman (BPS Padang Pariaman, 2019). Begitu juga terkait penerima bantuan, terdapat 36.637 KK di Basis Data Terpadu yang belum diverifikasi dan validasi secara maksimal.

Kemiskinan yang ada di Kabupaten Pariaman ini telah menjadi masalah pokok pembangunan Daerah Kabupaten Padang Pariaman yang tertera dalam Rancangan Kerja Pembangunan Daerah (RKPD). Tetapi pada pelaksanaannya masih belum menunjukkan hasil yang optimal, sehingga perlu ditingkatkan atau dikembangkan lagi. Penanganan kemiskinan bersifat parsial inilah yang menyebabkan tingginya angka kemiskinan di Kabupaten Padang Pariaman saat ini.

Hal ini dapat dibuktikan dari sering terjadinya pemberian bantuan yang tidak tepat sasaran yang disebabkan oleh OPD yang bergerak sendiri-sendiri dalam penanganan kemiskinan di Kabupaten Padang Pariaman ini. Salah satu bentuk upaya agar berkurangnya angka kemiskinan ini yaitu, dengan diciptakannya suatu inovasi pusat layanan di Kabupaten Padang Pariaman yang diberi nama Please Care Papa.
Seiring dengan dikeluarkannya Peraturan Bupati Padang Pariaman Nomor 30 Tahun 2019 tentang Pembentukan Pusat Layanan Terpadu Penanganan Kemiskinan. Pusat Layanan Terpadu Penanganan Kemiskinan yang Cepat, Akurat, Responsif, dan Efektif di Kabupaten Padang Pariaman yang familiar disebut dengan Please Care Papa. Please Care Papa merupakan suatu pusat layanan terpadu lintas sektoral yang Cepat, Akurat, Responsif dan Efektif untuk menyelenggarakan penanganan kemiskinan di Kabupaten Padang Pariaman yang membantu mengetahui keperluan masyarakat miskin berdasarkan profil dalam basis data terpadu yang menghubungkan masyarakat miskin dengan bermacam program perlindungan sosial serta penanganan untuk kemiskinan yang diselenggarakan oleh Pemerintah Pusat, maupun pemerintah daeran sesuai dengan kebutuhan masyarakat miskin.

Dinas Sosial Pemberdayaan Perempuan dan Perlindungan Anak Kabupaten Padang Pariaman atau yang sering disebut dengan DinsosP3A meresmikan Program Please Care Papa pada tanggal 24 Juni 2019. Program Please Care Papa diharapkan mampu menyatukan pelayanan kemiskinan yang ada dan memperkuat hubungan jejaring kerja antara instansi/ lembaga pemerintahan, non pemerintahan dan pemerintahan pusat maupun unit pelayanan sosial lainnya yang sesuai dengan kondisi dan kebutuhan daerah tersebut. Seluruh masyarakat yang sudah terdaftar didalam Basis Data Terpadu akan dapat melihat program bantuan apa saja yang sudah mereka terima seperti PKH (Program Keluarga Harapan), Bantuan Pangan Non Tunai, Bantuan Iuran Jaminan Kesehatan Nasional (PBIJKN) dan sebagainya. Bantuan tersebut bersumber dari Anggaran Pendapatan Belanja Negara (APBN), Anggaran Pendapatan Belanja Daerah (APBD) Propinsi dan Kabupaten, CSR maupun Perantau.

Berdasarkan hasil pengamatan yang penulis lakukan di DinsosP3A terkait Please Care Papa, ditemukan beberapa 
permasalahan, seperti masih banyak data masyarakat miskin yang belum di input ke Basis Data Terpadu (BDT) yang menyebabkan masyrakat miskin tersebut belum bisa menerima bantuan sosial karena belum terdaftar. Begitu juga dengan konfirmasi data yang tidak sesuai. Seperti, Nama dan NIK tidak cocok, adanya masyarakat yang telah pindah tempat tinggalnya, ada yang sudah mampu dan sejahtera, dan bahkan masih ada yang sudah wafat tetapi masih terdaftar menjadi pemeroleh bantuan. Sedangkan data tersebut akan dijadikan acuan sebagai penerima bantuan sosial ke depannya.

Pemberian bantuan juga masih belum tepat sasaran, karena masih adanya ditemui masyarakat yang sejahtera dan mampu namun masih saja menerima bantuan yang seharusnya untuk masyrakat miskin. Masih terdapat Human error yang mengakibatkan terjadinya kekeliruan teknis seperti salah memasukkan nomor KK, kesalahan dalam penginputan data, dan adanya data ganda. Kesalahan teknis pun menjadi permasalahan seperti mati lampu, terganggunya koneksi internet, hingga website Please Care Papa yang sering mengalami kerusakan (error).

Terkait tujuan penerapan Please Care Papa untuk memudahkan masyarakat miskin dalam menjangkau pelayanan sosial dan program bantuan sosial. Masyarakat merasa jika datang langsung ke kantor DinsosP3A Kabupaten Padang Pariaman pengaduan dan saran lebih cepat ditanggapi. Kebanyakan masyarakat tidak mengetahui adanya pelayanan secara online di DinsosP3A Kabupaten Padang Pariaman, ditambah lagi sasaran dari pelayanan online melalui website Please Care Papa ini adalah masyarakat miskin yang sejatinya memiliki kekurangnya akan pengetahuan dan kemampuan untuk memanfaatkan peralatan teknologi informasi dan komunikasi. Berdasarkan paparan latar belakang di atas penulis tertarik untuk meneliti lebih lanjut mengenai Dampak Budaya Kerja Aparatur Terhadap Kualitas
Pelayanan Pada Program Please Care Papa Di Kabupaten Padang Pariaman.

\section{TINJAUAN PUSTAKA}

\section{Pengertian Budaya Kerja}

Dengan merujuk pada Permen PAN dan RB No. 39 Tahun 2012 Pedoman Pengembangan Budaya Kerja Aparatur Negara, yang menyatakan bahwa Budaya Kerja merupakan" sikap dan tingkah laku individu atau kelompok yang telah menjadi watak bahkan tabiat serta didasari dengan nilai-nilai yang telah diyakini bahwa itu benar kemudian diterapkan dalam tugas dan pekerjaan sehari-hari.

(Frinaldi, 2014) berpendapat bahwa budaya kerja merupakan suatu acuan yang menjadi dasar baik secara terlihat ataupun tidak terlihat dalam diri seorang pegawai yang dilihat dari perspektif nilai, pemahaman dan kemampuan bagaimana cara bekerja, norma, serta pola pikir, dan sikap setiap pegawai dalam menjalankan suatu pekerjaan.

Sejalan dengan menurut (Kasandra, Frinaldi, \& Lanin, 2018) Budaya kerja pada suatu organisasi yang didasarkan dengan pedoman pada kualitas hidup sebagai nilai ke dalam perilaku ataupun sifat yang menjadi pendorong bagi segelintir masyarakat maupun pada suatu organisasi.

Terdapat enam indikator untuk melihat dan mengukur suatu budaya kerja pada organisasi, yaitu: (1)Kepemimpinan merupakan proses yang sangat mendorong dan mempengaruhi untuk pencapaian suatu tujuan pada organisasi. (2)Penampilan merupakan suatu keadaan maupun eksistensi individu dalam suatu ruang publik yang membuat kesan (3)Kesadaran akan waktu merupakan kesadaran untuk mengerjakan sesuatu yang harus sesuai dengan waktu yang telah ditentukan (4)Komunikasi adalah sebuah kemampuan bertutur kata, proses pengungkapan dalam interaksi(5)Penghargaan dan pengakuan adalah suatu pemberian reward atau punishment bagi pegawai yang meraih prestasinya dalam bekerja dan bagi yang melakukan pelanggaran ataupun 
penyimpangan pada saat bekerja(6)Nilai dan kepercayaan adalah sesuatu keyakinan yang mendasari perilaku seseorang dalam bekerja (Frinaldi, 2017).

Oleh karena itu dapat dikatakan budaya kerja mempunyai peran yang berguna terhadap organisasi. Penerapan budaya kerja tentu juga akan berpengaruh pada kegiatan maupun aktifitas serta keberlangsungan sesebuah organisasi yang berdampak baik sehingga menimbulkan sebuah citra yang baik di sebuah organisasi. (Frinaldi \& Embi, 2011)

\section{Pengertian E-government}

Bank Dunia (World Bank) berpendapat bahwa Electronic government merupakan pemanfaatan teknologi informasi oleh pemerintah untuk meningkatkan kinerja, teerkait dengan aktivitas koordinasi, berkomunikasi bahkan dalam pemeberian pelayanan kepada masyarakat. (Indrajit, 2006).

Sedangkan menurut Mustopadijaya electronic government bisa juga disebut dengan electronic administration. Sebutan ini diberikan bagi pemerintah yang menggunakan teknologi berbasis internet untuk meningkatkan kualitas pelayanan dan melengkapi program-program pelayanan (Habibullah, 2010).

\section{Dimensi Kualitas Pelayanan Publik Berbasis E-Government}

Electronic Government Quality (EGovQual) merupakan metode untuk menilai sistem informasi yang berbasis elektronik dalam memberikan pelayanan kepada masyarakat. Instrumen E-GovQual dikembangkan dengan menilai kualitas pelayanan yang diberikan oleh layanan Electronic Government berdasarkan perspektif pengguna akhir atau masyarakat terdapat 4 (empat) dimensi pada $E$ GovQual, yaitu dimensi efisiensi (efficiency), dimensi kepercayaan (trust), dimensi keandalan (reliability), dan dimensi pendukung (citizen support) (Papadomichelaki, 2012).

\section{METODE PENELITIAN}

Metode penelitian pada penelitian ini menggunakan metode kualitatif deskriptif. Lokasi pada penelitian ini dilakukan di daerah Kabupaten Padang Pariaman. Datadata dikumpulkan melalui studi dokumentasi, observasi dan metode wawancara. Teknik triangulasi digunakan untuk menguji keabsahan data yang menggunakan pihak luar untuk dijadikan pembanding sehingga bisa ditarik kesimpulan.

Pada penelitian inin pemilihan informan ialah menggunakan teknik purposive sampling. Terkait penelitian ini, informan haruslah didasarkan pada relevansi pengetahuan mengenai budaya kerja aparatur terhadap kualitas pelayanan pada program Please Care Papa di Kabupaten Padang Pariaman. Informan yang berkemungkinan berhubungan langsung dengan penelitian penulis yaitu:

Tabel 1. Informan Penelitian

\begin{tabular}{|l|l|l|}
\hline No & \multicolumn{1}{|c|}{ Nama } & \multicolumn{1}{|c|}{ Status } \\
\hline 1 & $\begin{array}{l}\text { Hendra } \\
\text { Aswara, } \\
\text { SSTP, MM }\end{array}$ & $\begin{array}{l}\text { Kepala Dinas } \\
\text { Ketua }\end{array}$ \\
\hline 2 & $\begin{array}{l}\text { Emri Nurman, } \\
\text { SSTP, MM }\end{array}$ & $\begin{array}{l}\text { Kabid } \\
\text { Pemberdayaan dan } \\
\text { Penanganan Fakir } \\
\text { Miskin }\end{array}$ \\
\hline 3 & $\begin{array}{l}\text { Drs. } \\
\text { Aprizondi, } \\
\text { MM }\end{array}$ & $\begin{array}{l}\text { Kabid } \\
\text { Perlindungan dan } \\
\text { Jaminan Sosial }\end{array}$ \\
\hline 4 & $\begin{array}{l}\text { Nofri Aznika } \\
\text { Putra, S.Sos }\end{array}$ & $\begin{array}{l}\text { Analis Pelayanan } \\
\text { Sosial }\end{array}$ \\
\hline 5 & Dedi Nursal & Staf Swakelola \\
\hline 6 & Yasri Ilyas & Wali Korong \\
\hline 7 & Emidarita & Masyarakat \\
\hline 8 & Mismanidar & Masyarakat \\
\hline 9 & Nurjannah & Masyarakat \\
\hline 10 & Reni & Masyarakat \\
\hline 11 & Linda wati & Masyarakat \\
\hline
\end{tabular}


Informan pada penelitian ini berjumlah sebanyak 11 orang dengan 5 orang pegawai DinsosP3A dan 6 orang masyarakat.

\section{HASIL DAN PEMBAHASAN}

\section{Dampak Budaya Kerja Aparatur terhadap Kualitas Pelayanan pada Program Please Care Papa di Kabupaten Padang Pariaman}

Untuk mengetahui dampak budaya kerja aparatur terhadap kualitas pelayanan pada program Please Care Papa di Kabupaten Padang Pariaman digunakan lah dua teori yaitu budaya kerja menurut (Frinaldi A. , 2017) dan kualitas pelayanan berbasiss $e$ government menurut (Papadomichelaki, 2012) dapat dilihat sebagai berikut:

\section{1) Budaya Kerja}

Menurut (Frinaldi A. , 2017), setidaknya terdapat beberapa unsur yang harus terpenuhi dalam budaya kerja sebagai berikut:

a. Kepemimpinan

Kepemimpinan pada Program Please Care Papa dapat dikatakan sudah baik, karena program ini merupakan hasil inovasi yang disusun langsung oleh Bapak Hendra Aswara selaku Kepala DinsosP3A yang mengikuti Pelatihan Kemimpinan Nasional Tingkat II (PKN) II di Lembaga Administrasi Negara (LAN). Dengan pengalaman dan kemampuan yang dimiliki pimpinan sangat cukup untuk menggerakan pegawai DinsosP3A untuk menyelenggarakan program Please Care Papa ini dengan baik. pimpinan rutin melakukan rapat bulanan untuk mengevaluasi terkait berapa banyak laporan yang masuk dan bagaimana tindakan terhadap laporan masuk tersebut.

b. Penampilan

Tampilan yang disediakan pada program Please Care Papa dapat dikatakann sudah sangat bagus, pada halaman utama ditampilkan informasi penting langsung terkait berapa jumlah KK (Kartu Keluarga), Data BDT (Basis Data Terpadu), Data PKH (Program Keluarga Harapan), dan Data BPNT (Bantuan Pangan Non Tunai) yang telah terdaftar pada program Please Care Papa. Tampilan dibuat dengan desain yang menarik dan mudah untuk dipahami masyarakat, dan ditambah dengan logo dari Kabupaten Padang Pariaman yang mencerminkan akuntabilitas untuk membangun citra yang positif dimata publik.

Namun hal tersebut belum berdampak baik terhadap kualitas pelayanan yang diberikan DinsosP3A melalui website Please Care Papa karena masyarakat mayoritas tidak mengetahui keberadaan website Please Care Papa ini.

c. Kesadaran akan waktu

DinsosP3A Kabupaten Padang Pariaman telah berupaya memberikan pelayanan untuk sebaik mungkin, begitu juga dengan kecepatan pelayanan yang diberikan, jika terdapat laporan masuk akan langsung diproses. Tetapi hal ini belum berdampak baik bagi kualitas pelayanan pada website Please Care Papa, karena masyarakat masih banyak yang melakukan pelayanan secara langsung dengan datang ke DinsosP3A.

d. Komunikasi

Komunikasi yang terjalin antar pegawai di Kantor DinsosP3A sudah baik, hal ini dapat dilihat dari cepatnya proses pertukaran informasi antar pegawai, yang biasanya dilakukan dengan melalui rapat. Tidak hanya melalui rapat untuk berkomunikasi para pegawai DinsosP3A juga tidak juga sudah menggunakan whatsaap, Zoom Meeting jika hendak berhubungan 
dengan pegawai yang sedang berjarak jauh.

Namun komunikasi kepada masyarakat terkait adanya pelayanan online melalui website Please Care Papa inilah yang masih buruk, karena DinsosP3A hanya melakukan satu kali sosialisasi mengenai website Please Care Papa ini, itupun tidak banyak masyarakat yang hadir. Ditambah lagi DinsosP3A terlihat tidak tertarik untuk mengadakan sosialisasi lebih lanjut kepada masyarakat dengan alasan susah untuk mengumpulkan masyarakat untuk melakukan sosialisasi. Hal ini lah yang menyebabkan masih banyaknya masyarakat yang tidak mengetahui adanya pelayanan online yang disediakan oleh DinsosP3A.

e. Penghargaan dan pengakuan

Masih kurangnya penghargaan dan pengakuan yang diberikan kepada pegawai, sehingga kurangnya motivasi yang tinggi dalam bekerja. Melakukan pelayanan kepada masyarakat merupakan pelayanan jasa, sehingga dibutuhkannya penghargaan bagi pegawai untuk menunjang kinerjanya sehingga pegawai tersebut juga bisa memberikan pelayanan yang berkualits kepada masyarakat.

f. Nilai dan kepercayaan

Nilai-nilai dan kepercayaan yang diterapkan di DinsosP3A berlandaskan pada maklumat pelayanan dan nilai-nilai kedisiplinan yang telah ada aturan bakunya yang harus diikuti. Dari hal ini terlihat bahwa pegawai DinsosP3A dalam melakukan pelayanan terpaksa dalam bekerja karena mengikuti aturan yang telah ditetapkan.
2) Kualitas Pelayanan Berbasis $E$ Government

Menurut (Papadomichelaki, 2012) untuk melihat kualitas pelayanan berbasis e-government dapat dilihat dari terpenuhinya empat unsur yaitu:

a. Efisiensi (Efficiency)

DinsosP3A telah membuat struktur situs website Please Care Papa dengan jelas dan mudah untuk diikuti oleh masyarakat. Informasi yang ditampilkan pada website Please Care Papa ini sudah cukup detail. Masyarakat bisa langsung mengetahui apakah terdaftar atau tidak sebagai penerima bantuan, dan juga program bantuan apa yang diterimanya. Untuk petunjuk terkait pengisian formulir pengaduanpun sudah tersedia. Hal ini tentu memudahkan masyarakat untuk menjangkau pelayanan sosial dan program bantuan sosial serta dengan adanya website Please Care Papa ini semua informasi terkait kesejahteraan masyarakat miskin bisa dengan mudah didapatkan.

Namun berbeda halnya dengan yang dialami oleh masyarakat yang menjadi sasaran dibentuknya pelayanan online ini, banyaknya masyarakat yang tidak mengetahui dan tidak mendapatkan informasi terkait adanya pelayanan online ini, karena kurangnya sosialisasi dari DinsosP3A tentang kegunaan dan manfaat dari layanan tersebut. Ditambah lagi rata-rata masyarakat miskin yang menjadi penerima manfaat ini merupakan masyarakat yang berusia lanjut. Meskipun masyarakat sudah mempunyai handphone yang bisa untuk mengakses internet, tetapi pemahaman masyarakat akan teknologi digital sangatlah rendah. Maka dari itu masyarakat lebih memilih untuk melakukan pelayanan secara langsung dengan mendatangi kantor DinsosP3A. 
Sehingga dapat dikatakan bahwa tidak efisiennya pelayanan online melalaui website Please Care Papa yang disediakan oleh DinsosP3A.

b. Kepercayaan (Trust)

DinsosP3A telah melakukan upaya untuk meningkatkan kualitas pelayanan terhadap masyarakat dengan menjamin keamanan penggunaan website Please Care Papa. DinSosP3A bekerja sama dengan Dinas Kependudukan dan Pencatatan Sipil agara data-data masyarakat yang digunakan terasip dengan aman. Begitu juga terkait keamanan ketika hendak melakukan pengaduan, nama dan informasi pelapor akan dirahasiakan. Hal ini tentu telah dapat membuat masyarakat percaya akan keamanan dari website Please Care Papa ini. Namun pada kenyataannya masyarakat tidak ada yang pernah mengakses ataupun melakukan pengaduan melalui website Please Care Papa. Masyarakatpun tidak bisa mempercayai sepenuhnya meskipun dengan adanya basis data terpadu yang menjadi acuan untuk pembagian bantuan. Karena, sering didapati pada saat pembagian bantuan masih terdapat nama warga yang sudah meninggal yang menjadi penerima bantuan dan dananya terpaksa dikembalikan. Hal ini tentu mengakibatkan kurangnya kuota yang seharusnya menerima bantuan. Sehingga dapat dikatakan masih rendahnya kepercayaan masyarakat terhadap pelayanan online ini.

c. Reliabilitas (Reliability)

DinsosP3A telah berupaya untuk mningkatkan kualitas pelayanan dengan terus memperbaharui basis data terpadu dalam waktu yang relative cepat yaitu sekali dalam tiga bulan. Website Please Care Papa ini juga bisa diakses melalui smartphone, jadi masyarakat bisa mengakses dan lebih mudah mendapatkan informasi terkait bantuan kapanpun dan dimanapun.

Namun masih terdapat masalah pada website Please Care Papa ini, pada saat hendak dibuka website sering mengalami gangguan (error). Tidak keluarnya informasi saat dilakukannya pencarian penerima bantuan. Sehingga dapat dikatakan website Please Care Papa ini masih belum layak untuk meningkatkan kualitas pelayanan berbasis $e$ government.

d. Dukungan Kepada Masyarakat (Citizen Support)

Dalam meningkatkan kualitas pelayanan terhadap masyarakat, DinsosP3A memiliki ketertarikan dan upaya untuk menyelesaikan masalah masyarakat miskin dalam penggunaan website Please Care Papa. Pegawai juga mempunyai pengetahuan untuk menjawab pertanyan pertanyaan masyarakat serta pegawai memiliki kemampuan untuk menyampaikan kepercayaan dan kenyaman kepada masyarakat. Namun pada kenyataannya belum ada masyarakat yang pernah merasakan pendampingan dan peminjaman handphone guna mengakses website Please Care Papa ini untuk melakukan pelayanan secara online. Sehingga dapat dikatakan bahwa DinsosP3A ini belum cukup membantu masyarakat dalam pemanfaat pelayanan online melalui website Please Care Papa ini.

\section{PENUTUP}

Berdasarkan hasil temuan penelitian yang telah dilakukan penulis tentang Dampak Budaya Kerja Aparatur Terhadap Kualitas Pelayanan Program Please Care Papa di Kabupaten Padang Pariaman, maka dapat ditarik kesimpulan antara lain:

Budaya kerja: a) Kepemimpinan. Kepemimpinan pada Program Please Care Papa dapat dikatakan sudah baik. Dengan 
pengalaman dan kemampuan yang dimiliki pimpinan sangat cukup untuk menggerakan DinsosP3A untuk menyelenggarakan program Please Care Papa ini dengan baik; b) Penampilan. Tampilan yang disediakan pada program Please Care Papa dapat dikatakan sudah sangat bagus, Namun hal tersebut belum berdampak baik terhadap kualitas pelayanan yang diberikan DinsosP3A melalui website Please Care Papa karena masyarakat mayoritas tidak mengetahui keberadaan website Please Care Papa ini; c) Kesadaran akan waktu. Kecepatan pelayanan yang diberikan berdampak baik bagi kualitas pelayanan pada website Please Care Papa, karena masyarakat masih banyak yang melakukan pelayanan secara langsung dengan datang ke kantor DinsosP3A; d) Komunikasi. Kurangnya sosalisasi kepada masyarakat dengan alasan susah untuk mengumpulkan masyarakat untuk melakukan sosialisasi. e) Penghargaan dan Pengakuan. Kurangnya penghargaan dan pengakuan yang diberikan kepada pegawai, sehingga kurangnya motivasi yang tinggi dalam bekerja; f) Nilai dan kepercayaan. Pegawai DinsosP3A dalam melakukan pelayanan terpaksa dalam bekerja karena mengikuti aturan yang telah ditetapkan.

Kualitas Pelayanan: a) Efisiensi (Efficiency). Tidak efisiennya pelayanan online melalaui website Please Care Papa yang disediakan oleh DinsosP3A, dikarenakan sasaran dari pengguna website ini adalah masyarakat miskin, yang sejatinya kurang mampu untuk membeli benda elektronik seperti smartphone dan kurangnya pengetahuan untuk menggunakan internet; b) Kepercayaan (Trust). Masih rendahnya kepercayaan masyarakat terhadap kualitas pelayanan pada program Please Care Papa ini. Karena masih belum tepat sasarannya pembagian bantuan kepada masyarakat; c) Reliabilitas (Reliability). Terdapat banyaknya masalah pada website Please Care Papa ini dimulai dari website yang sering error ketika hendak di aksess. Dan tidak munculnya informasi ketika dilakukan pencarian penerima bantuan; d) Dukungan Kepada Masyarakat (Citizen Support). Masih kurangnya pendampingan yang diberikan oleh pegawai DinsosP3A kepada masyarakat untuk melakukan pelayanan melalui website Please Care Papa.

\section{DAFTAR KEPUSTAKAAN}

Frinaldi, A. (2014). Pengaruh Budaya Kerja Pegawai Negeri Sipil Terhadap Pelayanan Publik di Dinas Catatan Sipil dan Kependudukan Kota Payakumbuh. HUMANUS.

Frinaldi, A. (2017). Mengelola Budaya Organisasi dan Budaya Kerja .Acuan Bagi Akademis, Praktisi, dan Pemerhati Budaya Kerja. UNP Press.

Frinaldi, A., \& Embi, M. A. (2011). Pengaruh Budaya Kerja Etnik Terhadap Budaya Kerja Keadilan dan Keterbukaan PNS Dalam Membangun Masyarakat Madani dan Demokrasi. Humanus, $X(1)$.

Habibullah, A. (2010). Kajian Pemanfaatan dan Pengembangan E-Government. Jurnal Fisip Unej, XXIII(3).

Indrajit, R. E. (2006). Electronic Government : Strategi Pembangunan dan Pengembangan Sistem Pelayanan Publik Berbasis Teknologi Digital. Yogyakarta: ANDI.

Kasandra, d., Frinaldi, A., \& Lanin, D. (2018). Pengaruh Budaya kerja Pengemudi Angkutan Umum Kota Terhadap Kepuasan Penumpang di Kota Padang. Spirit, 13 April(1).

Papadomichelaki, X. \&. (2012). eGovQual: A Multiple-item scale for assessing e-govenrment service quality. Government Information Quarterely.

Widayani, H. (2013). Upaya Penanganan Kemiskinan Serta Keamanan Dan 
Bella Kharisma Putri, Aldri Frinaldi I Dampak Budaya Kerja Aparatur terhadap Kualitas Pelayanan pada Program Plase Care Papa di Kabupaten Padang Pariaman

Ketertiban Masyarakat Di Kabupaten

Sleman (Studi pada Badan Keluarga

Berencana, Pemberdayaan

Masyarakat dan Pemberdayaan

Perempuan serta Polres Sleman).

Universitas Negeri Yogyakarta,

Faklutas Ilmu Sosial. Yogyakarta:

tidak dipublikasikan. 